\title{
Differential Laminar Distribution of Corticostriatal Neurons in the Prefrontal and Pericruciate Gyri of the Dog
}

\author{
Duke Tanaka, Jr. \\ Department of Anatomy, Michigan State University, East Lansing, Michigan 48824
}

\begin{abstract}
This investigation was undertaken to determine whether the laminar distribution of corticostriatal neurons differs between different anatomical and functional areas of the frontal lobe. Injections of lectin-conjugated horseradish peroxidase were made into the lateral, intermediate, and medial parts of the head of the caudate nucleus. After injections into the medial part of the caudate, most of the labeled neurons were found in the proreal and subproreal gyri of the prefrontal region. In both gyri, the majority of labeled cells were localized within layer $\mathbf{V}$, and fewer neurons were located in the deeper part of layer III and in layers IV (proreal gyrus) and VI. No labeled neurons were noted in layer II. This distribution contrasted with that seen following injections into the intermediate and lateral parts of the caudate nucleus. In those cases, the majority of labeled cells were located in the pericruclate reglon (areas 4 and 6 ) and on the medial and lateral banks of the presylvian sulcus (paraorbital and internal composite areas, respectively). In the paraorbital and internal composite areas, the majority of labeled cells were still localized within layer $\mathbf{V}$, but a larger percentage of labeled neurons were also noted in layer III. In areas 4 and 6, the laminar distribution shifted so that the majority of labeled cells were now located in layer III, with a widespread distribution of neurons throughout layers II-VI. These results indicate that corticostriatal neurons in the frontal lobe have different laminar distributions, depending on the particular anatomical or functional area in which they are located. The majority of neurons in the prefrontal region are located in infragranular layers, while those in the pericruciate region are located in supragranular layers.
\end{abstract}

The laminar organization of corticostriatal projection neurons has been the subject of much recent study. Several investigators, using retrograde transport techniques, have localized corticostriatal neurons to layer $\mathrm{V}$ in the rat (Hedreen, 1977; Wise and Jones, 1977; Veening et al., 1980) and monkey (Jones et al., 1977), while other studies in the cat (Kitai et al., 1976; Oka, 1980) and rat (Schwab et al., 1977) have shown that the majority of these neurons are located in layer III, with fewer numbers of cells distributed in layers V and VI. More recent studies in the

Received Feb. 25, 1987; revised June 8, 1987; accepted June 8, 1987.

I wish to thank Dr. Lori Isaacson and Ms. Beverly Kay Trosko for their assistance in the conduct of this study, Dr. Sharleen T. Sakai for helpful comments on the manuscript, and Ms. Judy James for typing the manuscript. This work was supported by NIH Grant NS16991 and a Biomedical Research Support Grant awarded to the College of Veterinary Medicine.

Correspondence should be addressed to Duke Tanaka, Jr., Department of Anatomy, A5 I 4 Fast Fee Hall, Michigan State University, Fast I ansing, MI 48824

Copyright (C) 1987 Society for Neuroscience $0270-6474 / 87 / 124095 \cdot 12 \$ 02.00 / 0$ cat (Royce, 1982, 1983; Kubozono et al., 1986) and monkey (Arikuni and Kubota, 1986) have reported that all cortical laminae except layer I contain neostriatally projecting neurons, of which the majority are located in layer III in the cat and layer $\mathrm{V}$ in the monkey. These observed variations in the laminar distribution of corticostriatal neurons may be attributable to differences in the degree of transport or sensitivity of the retrograde tracer used, or to differences associated with the species used. However, one additional factor that should be considered is the particular cortical area within which the corticostriatal neurons are found. It may be that the laminar distribution of these neurons varies between different anatomically or functionally identifiable cortical areas.

Previous studies have shown that the canine frontal lobe can be divided into several different and distinct functional areasthe prefrontal area, the supplementary motor and premotor areas, and the primary motor area (Brutkowski, 1964; Konorski, 1972; Górska, 1974). Each of these areas has been shown to possess distinctive cytoarchitectonic characteristics (Kreiner, 1961, 1964; Adrianov and Mering, 1964; Akert, 1964; Górska and Dutkiewicz, 1979; Tanaka et al., 1983; Stanton et al., 1986; Tanaka, 1987) and thalamic connections (Narkiewicz and Brutkowski, I967; Kosmal and Dabrowska, 1980; Kosmal, 1981a, b; Tanaka et al., 1983; Stanton et al., 1986). In addition, each area maintains scparate and distinct conncctions with the neostriatum (Tanaka et al., 1979, 1981; Tanaka, 1987). For example, projections from area 4 (primary motor cortex) are more topographically organized than are those from the prefrontal region, in which there is extensive overlap between projections from widely separated prefrontal gyri. Each major cortical area also projects most heavily to a specific sector of the caudate nucleus: area 4 projects to the dorsolateral corner, area 6 to the intermediate region, and the prefrontal cortex to the most medial portion. As part of a continuing investigation of corticostriatal organization in the dog, a study was initiated to determine whether these frontal lobe areas might also differ from one another in their laminar organization of corticostriatal neurons. Results indicate that differences in laminar distribution do exist, such that corticostriatal neurons in the prefrontal region are located primarily within layer $\mathrm{V}$, while those in areas 6 and 4 show a more widespread distribution, with the majority of labeled neurons located in layer III.

\section{Materials and Methods}

Results from 5 adult mixed-breed male and female dogs weighing between 8 and $10 \mathrm{~kg}$ each were used in this study. Prior to surgery, each animal was tranquilized with an intramuscular injection of ketamine hydrochloride $(10 \mathrm{mg} / \mathrm{kg})$ and acepromazine maleate $(0.8 \mathrm{mg} / \mathrm{kg})$ and anesthetized with an intravenous injection of sodium pentobarbital $(20$ 
Table 1. Percentage of retrogradely labeled corticostriatal neurons located in layers II-VI of prefrontal and pericruciate areas

\begin{tabular}{lcrrrrr}
\multicolumn{7}{l}{ Cortical area } \\
\cline { 2 - 7 } & $\begin{array}{l}\text { PRO }^{a} \\
(n=104)^{b}\end{array}$ & $\begin{array}{l}\text { SPR } \\
(n=76)\end{array}$ & $\begin{array}{l}\text { POR } \\
(n=107)\end{array}$ & $\begin{array}{l}\text { CJ } \\
(n=138)\end{array}$ & $\begin{array}{l}\text { Area 6 } \\
(n=121)\end{array}$ & $\begin{array}{l}\text { Area 4 } \\
(n=93)\end{array}$ \\
\hline II & 0.0 & 0.0 & 0.0 & 0.0 & 0.0 & 7.5 \\
III & 1.9 & 7.9 & 20.6 & 23.9 & 54.6 & 65.6 \\
V & 90.4 & 89.4 & 73.8 & 71.7 & 41.3 & 18.3 \\
VI & 1.9 & 2.6 & 5.6 & 4.4 & 4.3 & 8.6
\end{tabular}

${ }^{3}$ Layer IV contained $5.8 \%$ of labeled proreal gyrus neurons.

${ }^{b} n$, Total number of retrogradely labeled neurons contained within a single 1.75.0 min strip of cortex taken from cases D8408L (PRO), D8406 (SPR), D8504 (POR, CJ, area 6), and D8404 (area 4).

$25 \mathrm{mg} / \mathrm{kg}$ ). In each case, the sodium pentobarbital injections were supplemented during surgery up to a maximal total dose of $40 \mathrm{mg} / \mathrm{kg}$. Unilateral injections of $0.15-0.5 \mu \mathrm{l}$ of $2.5 \% \mathrm{WGA}-\mathrm{HRP}$ were made into the head of the caudate nucleus in 4 animals, while in one dog a bilateral injection of $0.2 \mu \mathrm{l}$ WGA-HRP was delivered. All injections were made through a dorsal approach and were placed in the dorsolateral, intermediate, and medial regions of the caudate nucleus (Fig. 1). Following survival periods of $2 \mathrm{~d}$, the dogs were reanesthetized and perfused intracardially with a $1.5 \%$ paraformaldehyde- $1.0 \%$ glutaraldehyde solution in $0.1 \mathrm{~m}$ phosphate buffer. This was followed immediately by a cold $10 \%$ sucrose buffer solution. The brains were blocked, placed in $30 \%$ sucrose buffer for $2 \mathrm{~d}$, frozen, cut in the coronal plane at $35 \mu \mathrm{m}$, and processed using tetramethylbenzidene (TMB) (Mesulam, 1982) or diaminobenzidene (DAB) with glucose oxidase (Itoh et al., 1979) as the chromagen. Sections were then counterstained with neutral red or thionin.

Three different methods were used to document the laminar distribution of corticostriatal neurons. First, in order to illustrate the laminar locations of labeled corticostriatal neurons and their relationships to unlabeled neurons, camera lucida drawings were made of all labeled and unlabeled cells in laminae I-VI in selected areas of each major cortical region. Dark-field photomicrographs were also taken of major cortical areas to document further the similarities and differences between the laminar distributions of labeled neurons. Finally, in order to quantify the laminar distribution of corticostriatal neurons, labeled cells across all laminae within a given cortical strip (bin) were counted within each prefrontal and pericruciate area examined. Cells were counted in areas showing the highest labeling density for that particular cortical area. The widths of the cortical bins ranged from $1.7 \mathrm{~mm}$ in pericruciate and presylvian areas to $5.0 \mathrm{~mm}$ in the prefrontal gyri, where labeled cells were fewer and widely scattered. The percentage of labeled neurons distributed within each cortical lamina was then calculated and tabulated.

\section{Results}

\section{Injection site and topography}

The effective site of WGA-HRP uptake in each case appeared to be restricted to the caudate nucleus. Sections processed with DAB showed that both the central core and halo of the WGAHRP injection sites were contained within the caudate nucleus. Very light halos of label were noted in the internal capsule and corpus callosum after processing with TMB, but the absence of retrograde neuronal labeling in specific thalamic relay nuclei and in the parietal cortex immediately surrounding the injection track indicated that these halos did not contribute to the overall labeling patterns observed.

The combined area encompassed by the 6 individual injections of WGA-HRP covered the entire lateral-medial extent of the head of the caudate nucleus (Fig. 1). The more laterally placed injections (cases D8404 and D8408R) resulted in large numbers of labeled cells in area 4 , with somewhat fewer labeled neurons in area 6 . The single large injection into the intermediate

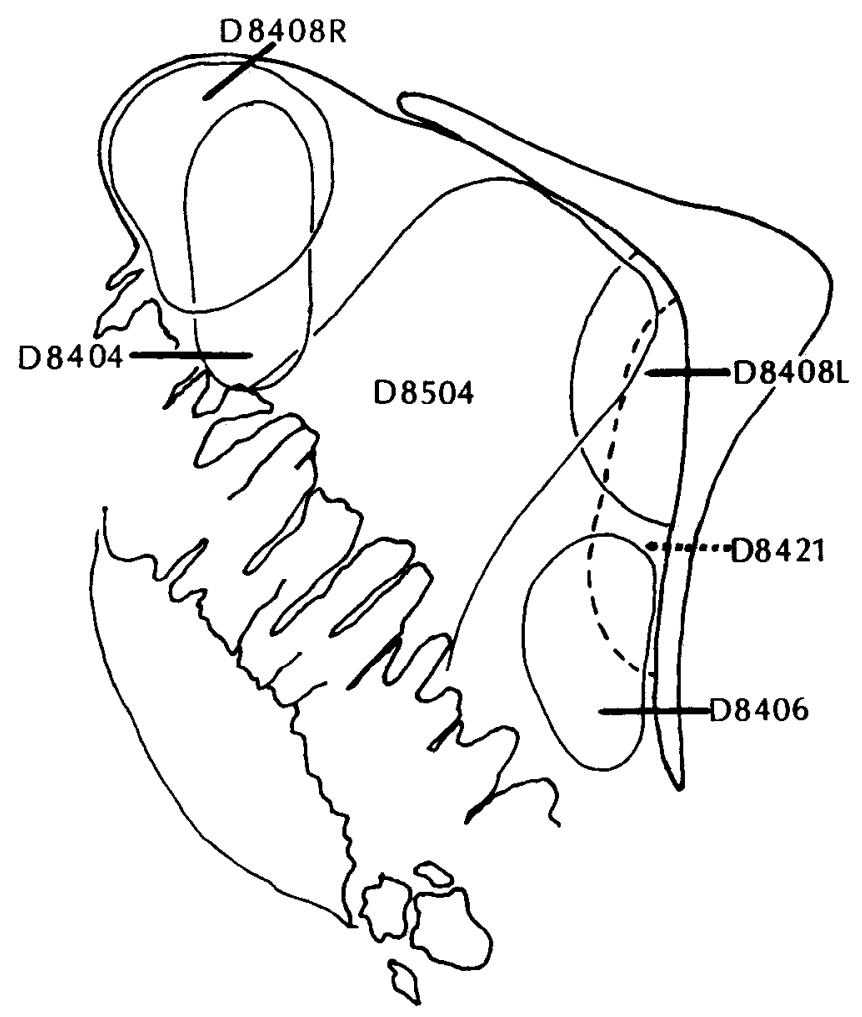

Figure 1. Diagram illustrating the extent and locations of WGA-HRP injections into the head of the caudate nucleus. The dorsolateral injection in case D8408R was transposed from the right to the left caudate to facilitate comparisons of injection sites.

part of the caudate in case D8504 resulted in very heavy labeling in area 6 , with slightly less label in both area 4 and the prefrontal region. The medially placed injections in cases D8406, D8421, and D8408L yielded heavy label in the prefrontal region, particularly within the proreal, subproreal, and paraorbital gyri.

\section{Laminar organization}

Prefrontal region. The cytoarchitecture of the canine prefrontal cortex has been described in detail in previous publications (Kreiner, 1961; Akert, 1964; Narkiewicz and Brutkowski, 1967; Kosmal et al., 1984; Tanaka, 1987). This region has been divided into 6 identifiable gyri, 3 of which - the proreal (PRO), subproreal (SPR) and paraorbital (POR)-are the subjects of the present study. The proreal and subproreal gyri are located on the dorsal and ventral aspects of the prefrontal region, respectively, while the paraorbital area forms the medial bank of the presylvian sulcus. Of these 3 regions, only the proreal gyrus has a definable layer IV. In the subproreal gyrus and paraorbital area, the borders between layers III and V are marked by changes in cell size and density. The relatively dense population of smalland medium-sized cells in layer III contrasts with the fewer and larger neurons noted in layer V. In the proreal gyrus, a neurondense layer IV is interposed between layer III, which is less densely populated, and layer $\mathrm{V}$, which contains small- and medium-sized pyramidal cells. In each gyrus, layer $\mathrm{V}$ is thin and merges gradually with the underlying layer VI.

An additional cortical area, the internal composite area (CJ) of Kreiner (1964), was included for analysis. This area is located along the lateral bank of the presylvian sulcus and, along with the paraorbital area, has been defined as forming a transitional 

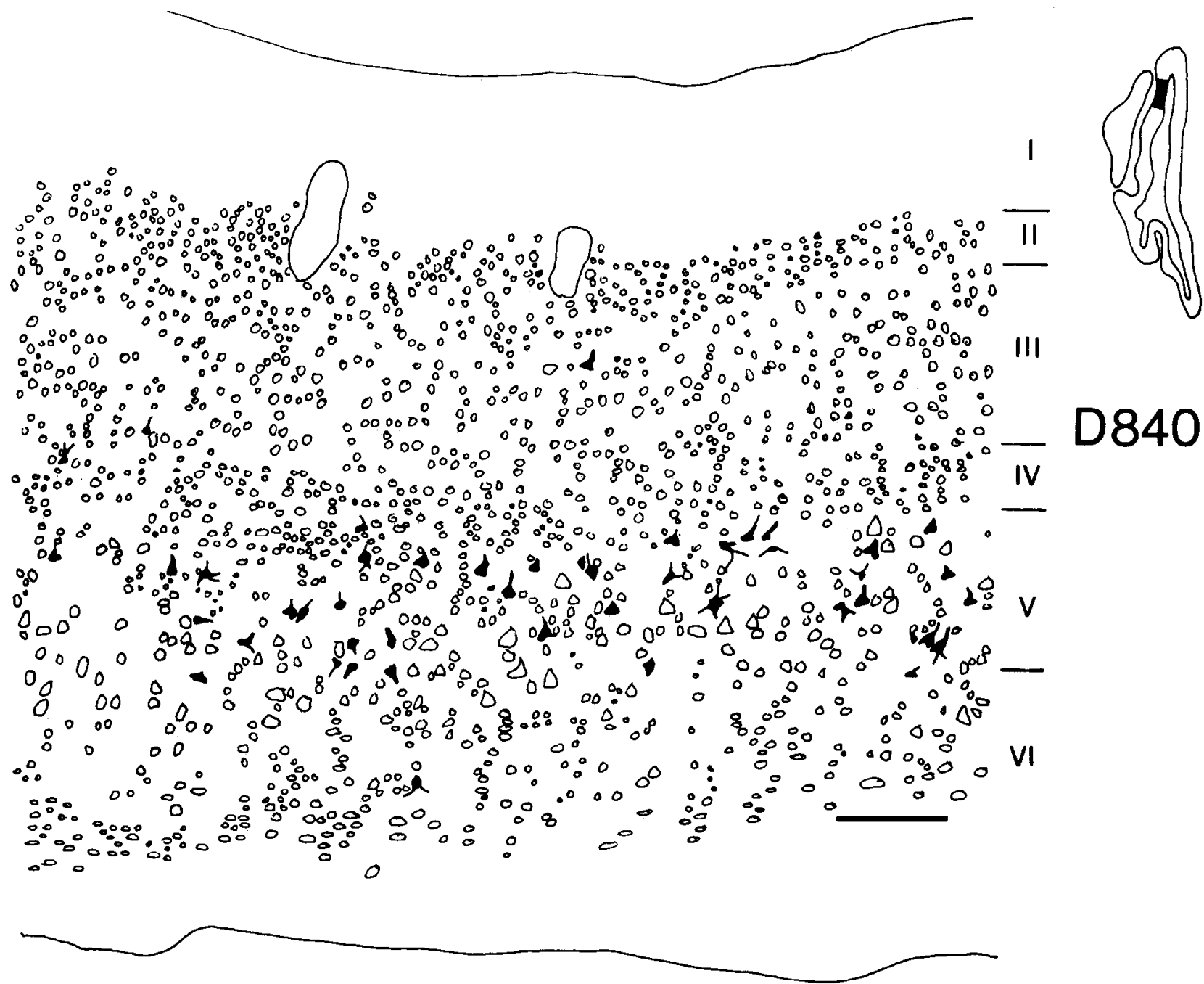

D8408L

$\therefore$

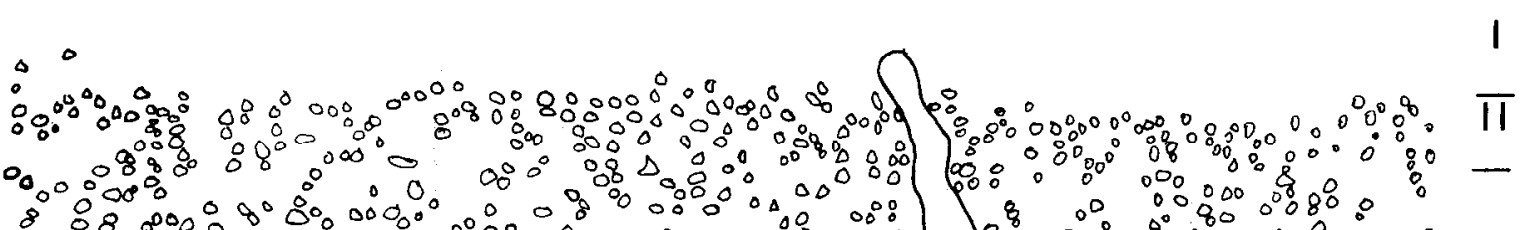

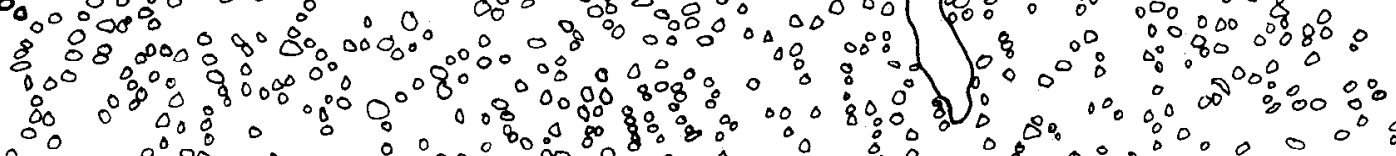

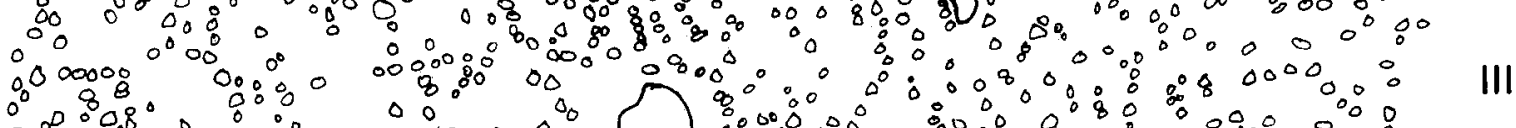

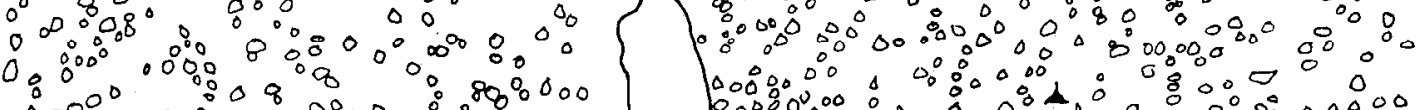

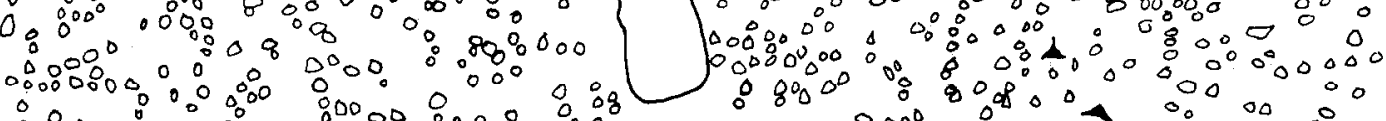

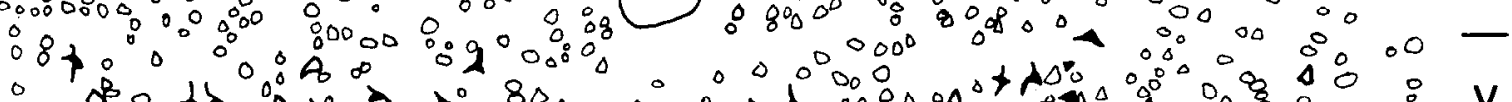

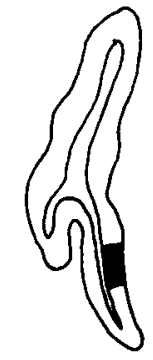

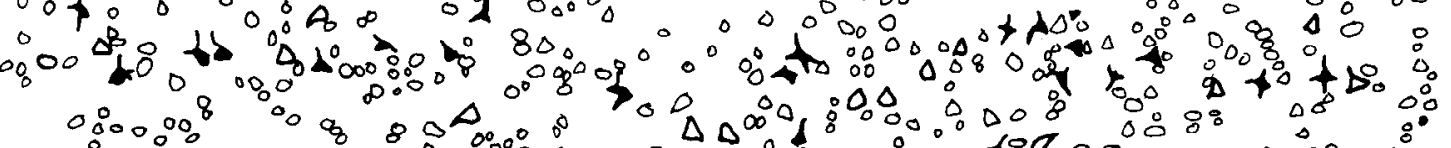

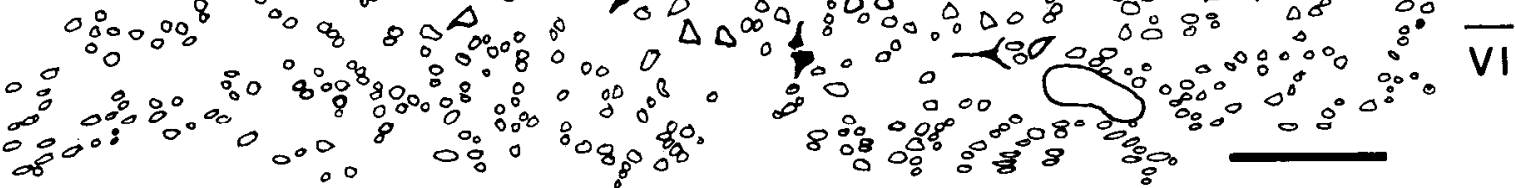

D8406

Figure 2. Camera lucida drawings of labeled (solid) and unlabeled (open) neurons in the proreal gyrus of case D8408L following a WGA-HRP injection into the dorsomedial part of the caudate nucleus, and in the suproreal gyrus of case D8406 after a WGA-HRP injection into the ventromedial part of the caudatc. Note the presence of a laycr IV in the prorcal gyrus and the narrow bands of labeled cells in layer V of both cases. The blackened areas on the cortical cross sections indicate the locations of the areas shown. Scale bars, $200 \mu \mathrm{m}$. 

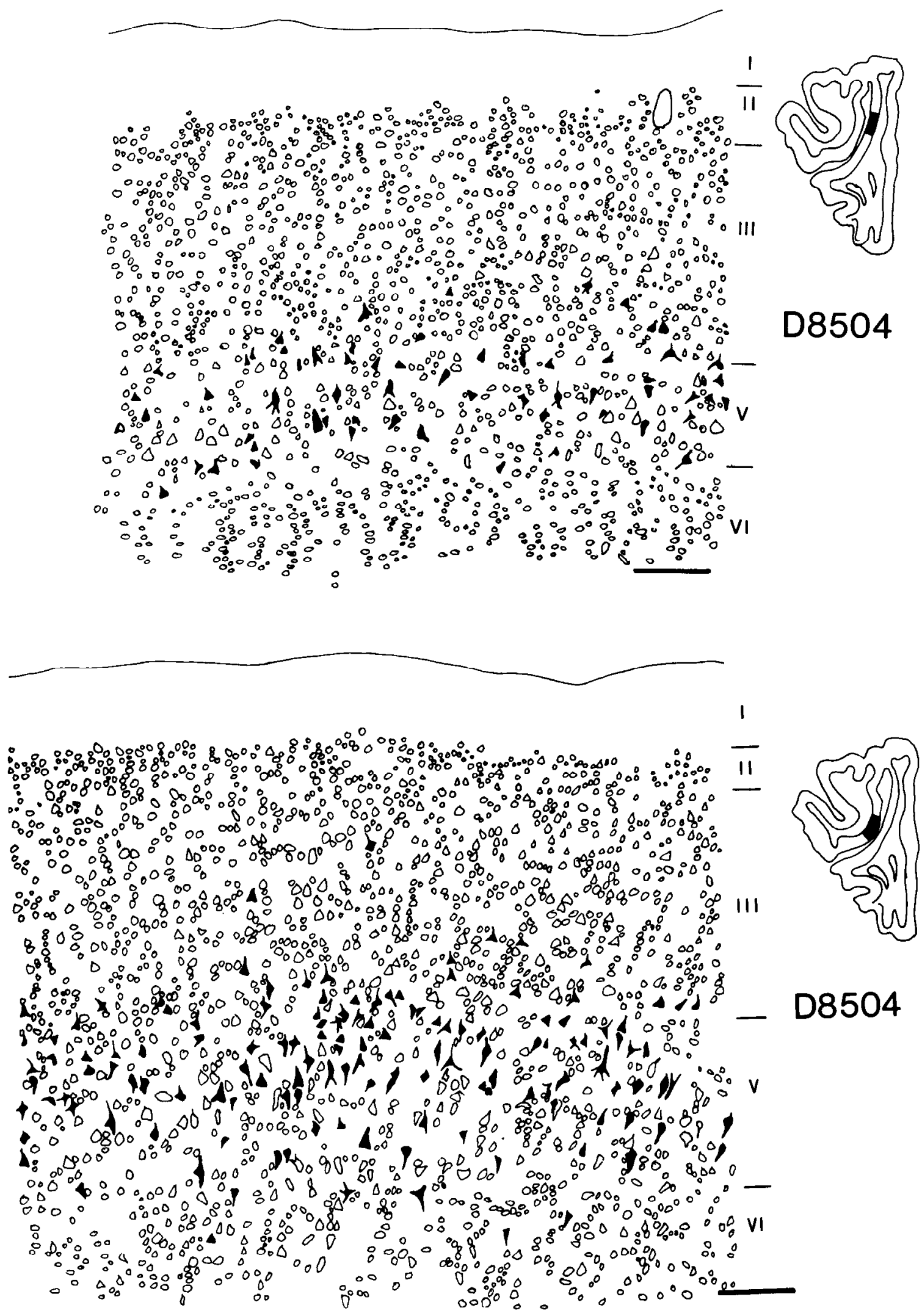

Figure 3. Camera lucida drawings of labeled (solid) and unlabeled (open) neurons in the paraorbital area (top) and internal composite area (bottom) of case D8504 following a WGA-HRP injection into the intermediate part of the caudate nucleus. Note that although the majority of labeled neurons are located in layer V, there are also a number of labeled cells in layer III, particularly within its deeper portion. A well-defined layer IV cannot be distinguished in either area. Scale bars, $200 \mu \mathrm{m}$. 

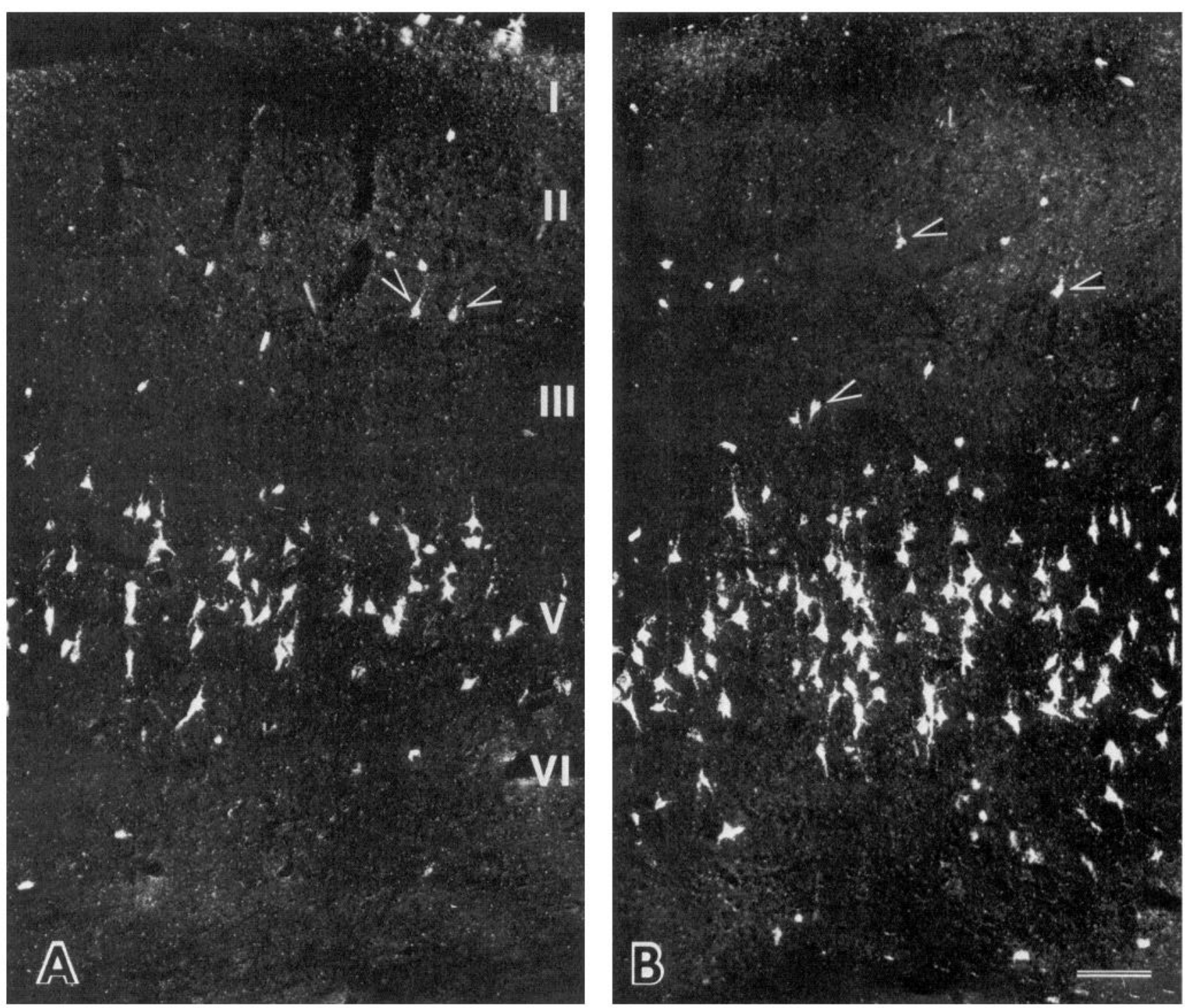

Figure 4. Dark-field photomicrographs illustrating the laminar distribution of retrogradely labeled corticostriatal neurons in the paraorbital $(A)$ and internal composite $(B)$ areas lying on the banks of the presylvian sulcus in case D8504. Note that the majority of labeled neurons are located within layer V. Fewer labeled neurons are located in the deep part of layer III, and only isolated labeled cells (arrowheads) are present in the more superficial part of layer III. Scale bar, $100 \mu \mathrm{m}$.

zone between the prefrontal region and the motor cortex (Kosmal et al., 1984). It is distinct from the paraorbital area in that it has a wider layer $\mathrm{V}$, containing large numbers of mediumsized pyramidal cells. Layer III, which is more cell-dense than the underlying layer $\mathrm{V}$, also contains scattered medium-sized pyramidal cells.

In each of the prefrontal areas, the majority of labeled neurons were located within layer V (Table 1) and consisted of smallto medium-sized pyramidal cells. In the proreal gyrus, a narrow band of retrogradely labeled and evenly distributed cells was located in the superficial part of layer V (Figs. 2, top, 7B). The deeper part of layer III and the superficial part of layer VI contained only isolated labeled cells. Layer IV, which is easily distinguishable only in the proreal gyrus, contained a small number of labeled cells as well. No labeled neurons were detected in layer II. In the subproreal gyrus, retrograde labeling was relatively sparse (Fig. 2, bottom). Labeled neurons formed a thin band, at times only one neuron deep, within the more superficial part of layer V. A few widely scattered neurons were noted within the deeper part of layer III and in the superficial part of layer VI. No labeled neurons were noted in layer II. Labeled corticostriatal neurons in the paraorbital area (Figs. 3, top, 4A) were localized within layer $\mathrm{V}$, with fewer neurons situated in the deeper part of layer III. Small clusters of labeled cells and single neurons were also noted in the superficial parts of layers III and VI (Fig. 4A). No labeled cells were detected in layer II. In the internal composite area, large numbers of retrogradely labeled cells were concentrated in layer $\mathrm{V}$, with a moderate number of neurons also labeled in the deeper part of layer III (Figs. 3, bottom, $4 B$ ). The labeled cells appeared to be somewhat larger then those located in the paraorbital area. No labeled neurons were detected in layer II and only scattered cells were noted in layer VI and in the superficial part of layer III.

Area 6. Area 6 in the dog can be divided into 2 subareasarea $6 \mathrm{a} \alpha$ and area $6 \mathrm{a} \beta$ (Stanton et al., 1986). Area $6 \mathrm{a} \beta$, from which the neuron counts and illustrations were obtained in the 


\section{D8504}

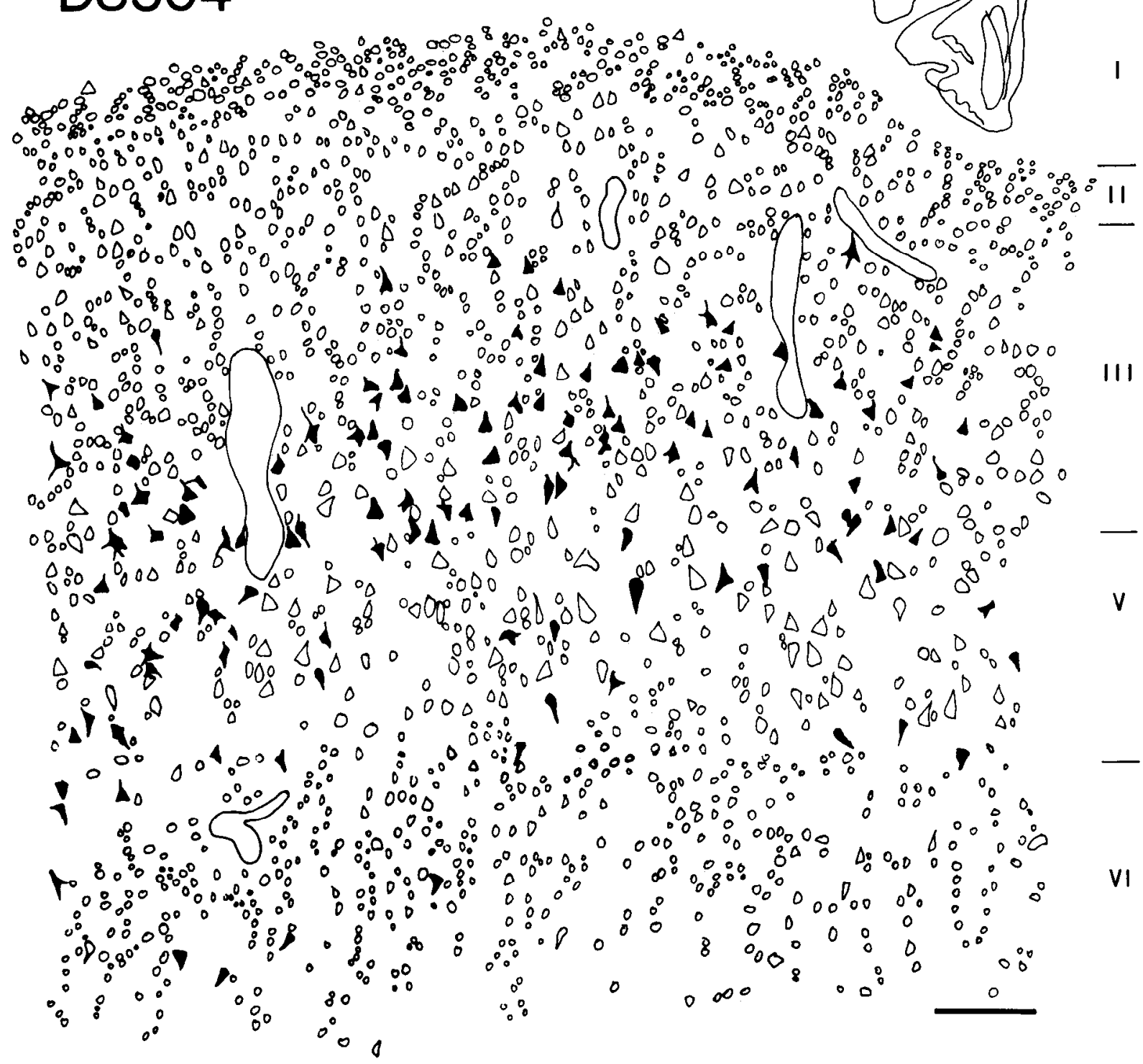

Figure 5. Camera lucida drawing of labeled (solid) and unlabeled (open) neurons in the medial part of area $6 \mathrm{a} \beta$ on the anterior sigmoid gyrus of case D8504. The WGA-HRP injection was placed in the intermediate part of the caudate nucleus. Note the wide distribution of labeled neurons, with the majority of cclls located in the decper part of layer III and in the superficial part of layer V. A few labeled cells are also present in layer VI. In this particular sector, no cells were noted in layer II. Scale bar, $200 \mu \mathrm{m}$.

present study, is located in the midregion of the anterior sigmoid gyrus and extends caudally into the anterior bank of the cruciate sulcus. Cytoarchitectonically, this area contains medium and large pyramidal cells in a well-developed layer V. It lacks a layer IV and the boundary between layers V and VI is marked by an abrupt change in cell size and density; layer $\mathrm{V}$ contains larger and more widely spaced neurons, while layer VI is made up of clumps of closely spaced small cells.

The laminar organization of labeled cells in area 6 differed from that seen in the prefrontal cortex in that neurons in portions of area 6 showed a more widespread distribution, with groups of labeled cells extending from layer II through layer VI (Figs.
$5,6,7 A)$. In the medial part of area $6 \mathrm{a} \beta$ the majority of labeled cells were located in the deeper part of layer III and in the adjacent superficial part of layer V (Table 1; Fig. 5), and very few neurons were noted in layers II or VI. However, in the lateral part of area $6 \mathrm{a} \beta$ labeled neurons were distributed more evenly throughout the cortical laminae, forming loosely organized columns of cells extending from layer II into layer VI (Figs. 6, 7A).

Area 4. Rustrally, area 4 begins on the most lateral extent of the anterior sigmoid gyrus, swings around onto the rostral border of the posterior sigmoid gyrus, and extends into the caudal bank of the cruciate sulcus (Górska and Dutkiewicz, 1979; Ta- 
naka et al., 1983). It is characterized cytoarchitectonically by the presence of large and giant pyramidal cells in layer $\mathrm{V}$ and the absence of a layer IV. Layer V is thin and has a low cell density when compared to the adjacent layer III.

The location of labeled neurons within area 4 showed a distinct shift toward the supragranular layers (Figs. 8, 9). Compared to both the prefrontal region and area 6 , area 4 contained a larger percentage of labeled cells within layers II and III, while the percentage of labeled cells in layer $\mathrm{V}$ was much reduced (Table 1). Labeled neurons consisted mostly of medium and small pyramidal cells.

\section{Discussion}

\section{Injection site}

In analyzing the present data, one factor that must be considered is whether leakage of WGA-HRP, either into the area surrounding the injection site or into the cortex and white matter surrounding the injection track, might have resulted in some of the reported cortical label. Examination of the injection sites using cobalt-chloride-intensified DAB revealed that the central core and halo were both contained within the caudate nucleus. In cases D8504 and D8404, processing of the injection site with TMB revealed a larger area of very light label that encompassed parts of the internal capsule and corpus callosum. However, several investigators (Mesulam, 1982; Shook et al., 1984) have reported that transport of WGA-HRP occurs only from the central, densely stained region of a TMB-delimited injection site and not from the lightly stained periphery.

In each case, the injection was made through a vertical approach, with the needle passing through the posterior parietal area and the cingulate gyrus on its way to the caudate nucleus. No cell labeling was detectable in the parietal cortex immediately surrounding the injection site. In addition, no retrogradely labeled neurons were found in the dorsal division of the ventral lateral nucleus, the lateral posterior nucleus, or the pulvinar, all of which have been shown to project to the posterior parietal cortex in the dog (Lewis et al., 1981). No labeled neurons were found in the thalamic anterior nuclear group, suggesting that no label was deposited in the cingulate gyrus. However, it should be noted that the cingulate gyrus did contain retrogradely labeled neurons in cases in which the injections were made into the dorsolateral portion of the caudate nucleus. We believe that the labeled cells seen in the cingulate gyrus in these cases were retrogradely filled by the WGA-HRP injections into the caudate nucleus. It has been shown that corticostriatal projections from the cingulate gyrus are localized within the dorsal part of the caudate in both the cat (Kubozono et al., 1986, using HRP) and dog (D. Tanaka, unpublished results from autoradiographic injections). Consistent with these results are the present findings that injections passing through the cingulate gyrus and terminating in the ventromedial part of the caudate result in no cell labeling in the cingulate cortex.

Finally, the results regarding cell labeling in laminac $\mathrm{II-VI}$ in the pericruciatc region are similar to the data reported previously by Royce in the cat (1982). He has shown that widespread laminar labeling can also be seen in the feline pericruciate cortex even after direct injections into the caudate nucleus following cortical aspiration. Thus, in the present study it is unlikely that incidental labeling of cortical or white matter areas contributed significantly to the overall labeling pattern observed in the frontal cortex.
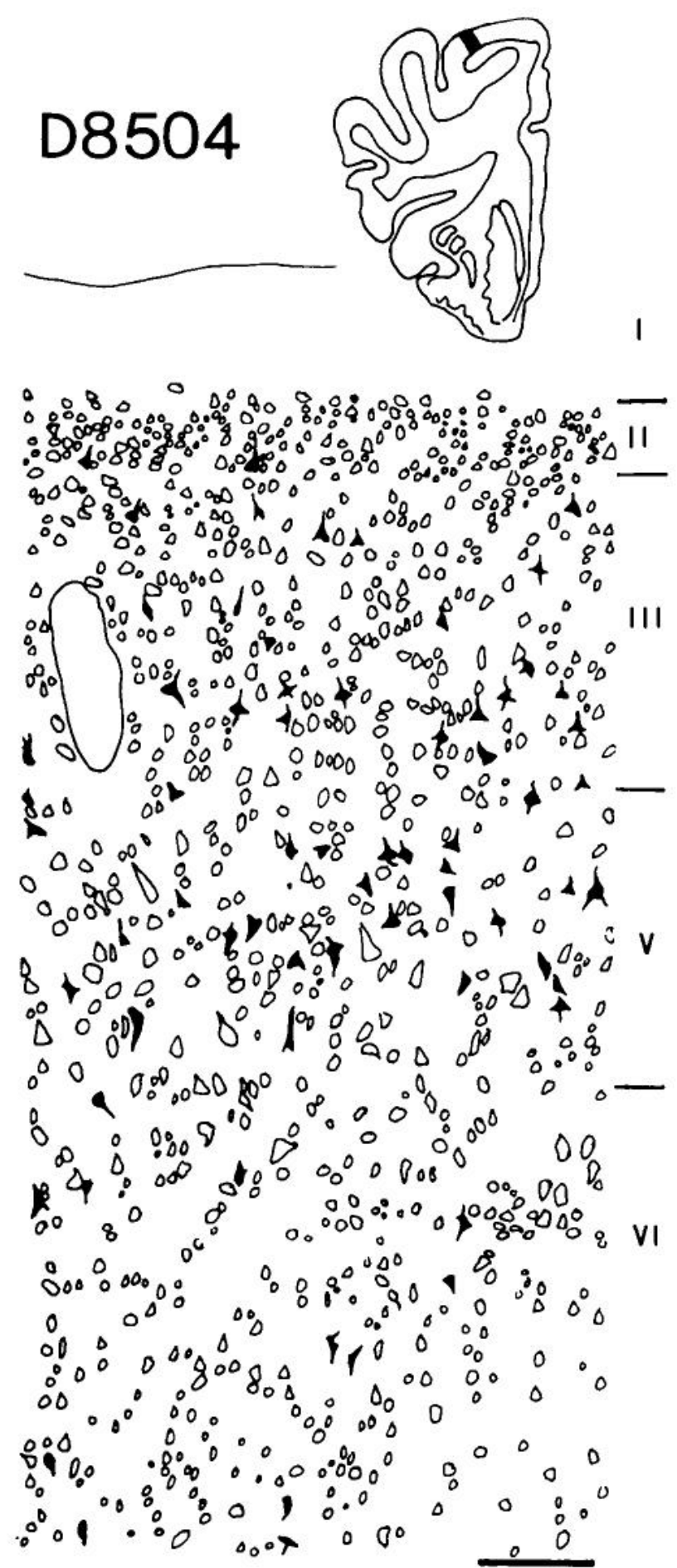

Figure 6. Camera lucida drawing of labeled (solid) and unlabeled (open) neurons in the latcral part of arca $6 \mathrm{a} \beta$ adjacent to arca 4 on the anterior sigmoid gyrus of case D8504. Note the spread of labeled cells into the more superficial part of layer III and into layer II. The WGA-HRP injection was placed in the intermediate area of the caudate nucleus. Scale bar, $200 \mu \mathrm{m}$.

\section{Laminar organization}

The results of the present study indicate that the laminar distribution of corticostriatal neurons may differ between anatomically and functionally defined cortical areas in the frontal lobe. In the prefrontal region, the number of labeled cells contained 


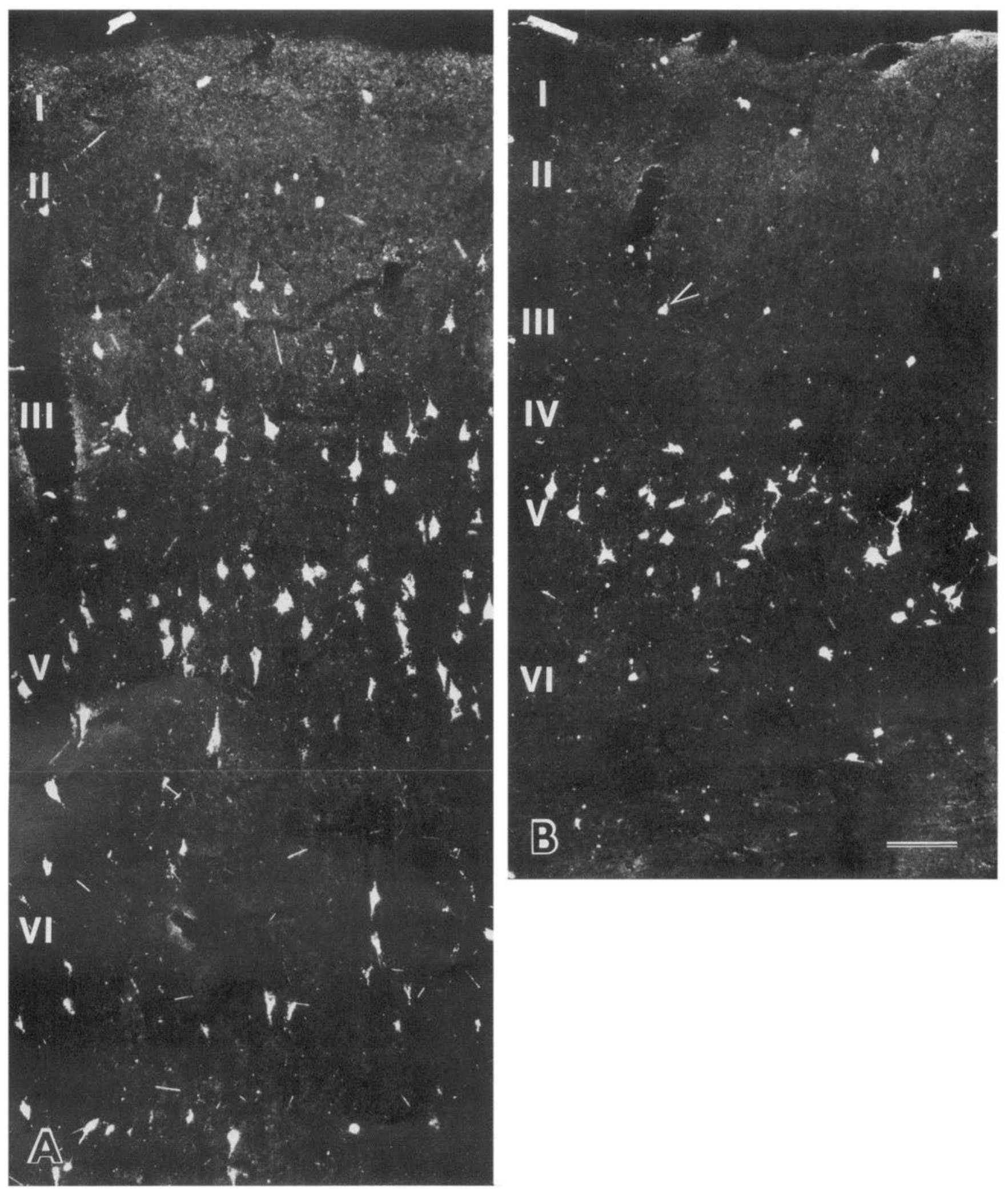

Figure 7. Dark-field photomicrographs illustrating the distribution of retrogradely labeled neurons in area $6 \mathrm{a} \beta$ in case D8504 $(A)$ and in the proreal gyrus in case D8408L $(B)$. Note the wide dispersion of cells extending from layer II into layer VI in area $6 a \beta$ and the narrow band of labeled cells confined to layer V in the proreal gyrus. The arrowhead in $B$ points to a single labeled neuron in layer III. Scale bar, $100 \mu \mathrm{m}$. 


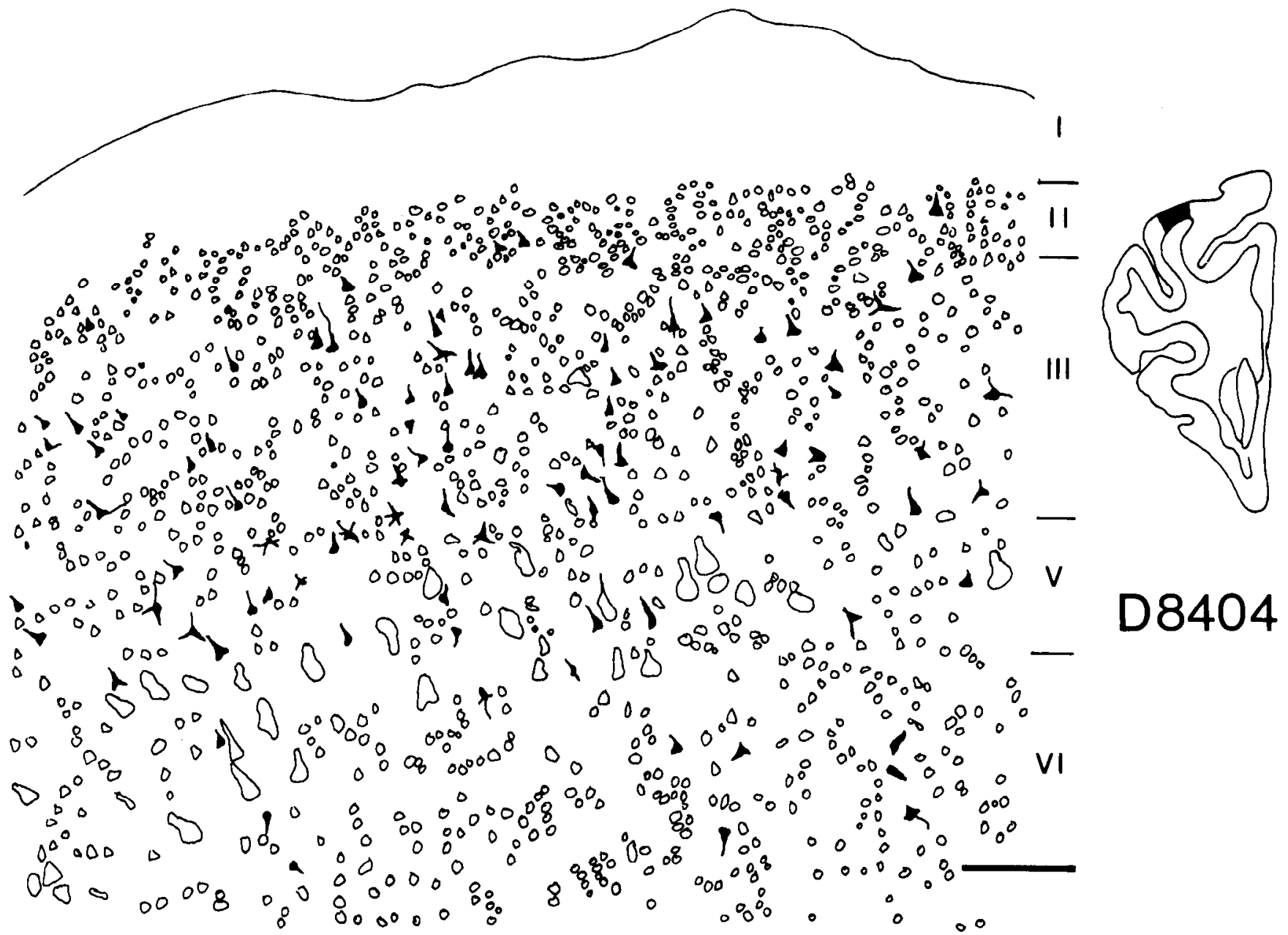

Figure 8. Camera lucida drawing of labeled (solid) and unlabeled (open) neurons in area 4 on the posterior sigmoid gyrus of case D8404. Note that the majority of labeled neurons are located in layer III and that labeled neurons are scattered throughout layers II-VI. Scale bar, $200 \mu \mathrm{m}$

within the infragranular layers far exceeded those located within supragranular layers. Overall, it appears that the major focus for prefrontal corticostriatal neurons is in layer V. Small numbers of neurons may also be located in layers III, IV (when present), and VI, although layer II was totally devoid of label in any of the gyri examined. There is also some evidence for laminar differences between different gyri in the prefrontal region. For example, in both the proreal and subproreal gyri, the distribution of labeled cells appears to be confined to a narrow horizontal band within layer V. In the paraorbital area, the labeled neurons are not confined to a narrow band but are spread over a wider portion of layer $\mathrm{V}$ and intrude in significant numbers into the deeper part of layer III. A similar picture is present in the internal composite area, which lies on the lateral bank of the presylvian sulcus. According to Kosmal et al. (1984), the banks of the presylvian sulcus in the dog are thought to comprise a transition area between prefrontal and motor cortical areas in terms of cytoarchitecture and corticocortical connections. Thus it is of interest that the distribution of corticostriatal neurons within the paraorbital and internal composite areas is also transitional between the prefrontal configuration seen in the proreal and subproreal gyri and that seen in area 6 . Area 6 shows a much denser distribution of corticostriatal neurons within layer III and a definite decrease in the percentage of labeled neurons in layer V, compared to the prefrontal region. Small numbers of labeled cells have also begun to appear in layer II in isolated areas. Within area 4 , labeling in layer III has reached its peak, and compares favorably with the percentages of layer III corticostriatal neurons reported in the cat by Kitai et al. (1976), Oka (1980), Royce (1982), and Kubozono et al. (1986). A number of corticostriatal neurons have also become evident in layer II, while the percentage of retrogradely labeled neurons located in layer $\mathrm{V}$ has decreased markedly. Taken together, these data suggest that the laminar distribution of corticostriatal neurons undergoes a gradual change from infragranular layers in the prefrontal region to supragranular layers in area 4.

Previous authors have also commented on differences in the laminar distribution of corticostriatal neurons. In their HRP study of the topography of corticostriatal neurons in the cat, Kubozono et al. (1986) briefly mentioned that the percentages of retrogradely labeled neurons appeared to vary from region to region. However, their quantitative data only dealt with the pericruciate region, where they found a 3:1 ratio between supragranular and infragranular label.

Arikuni and Kubota (1986) also remarked on areal differences in the laminar distribution of corticostriatal neurons in the prefrontal cortex of the monkey. They found that the laminar organization of labeled cells changed within diverse regions of the 


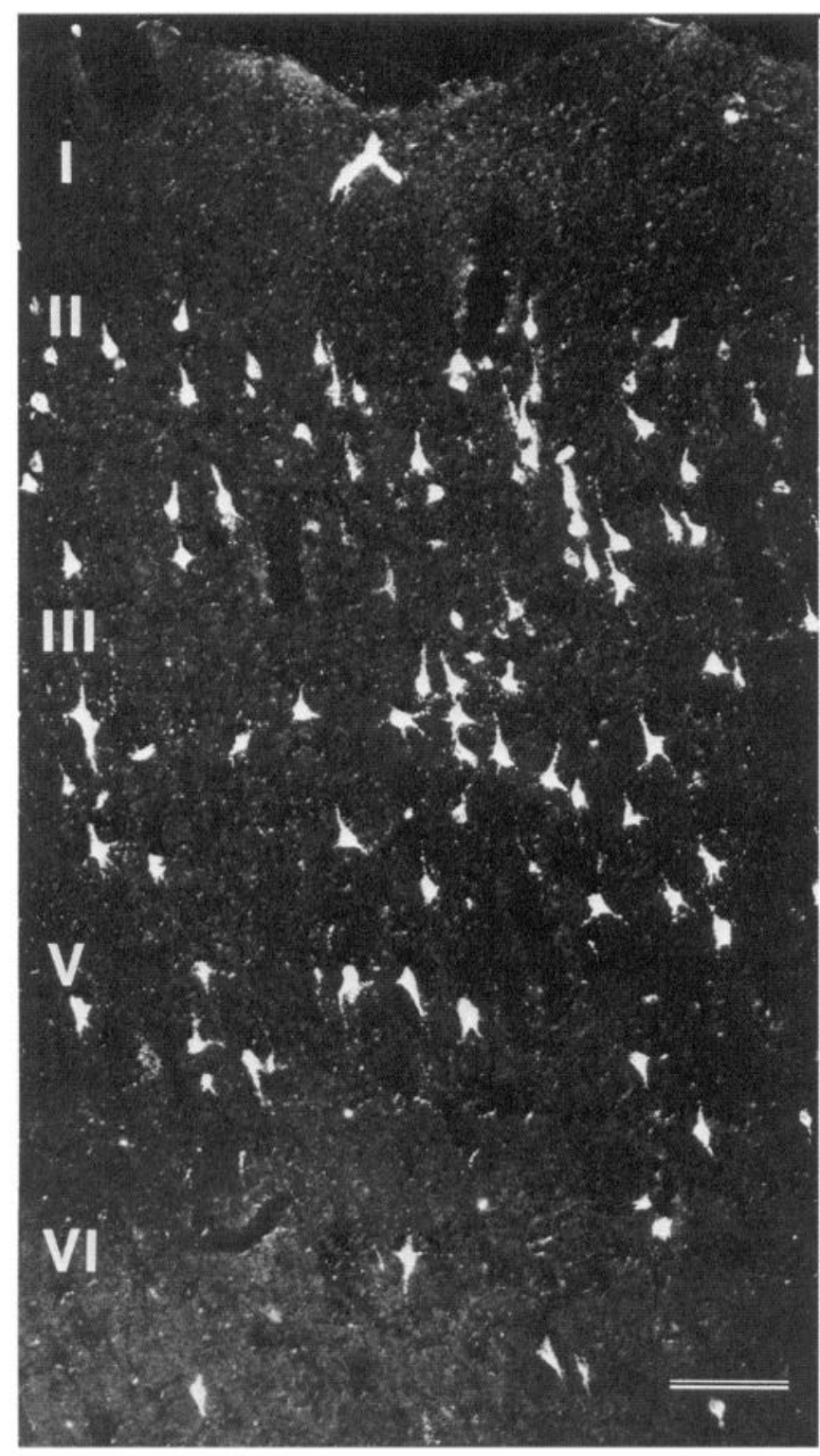

Figure 9. Dark-field photomicrograph showing the distribution of retrogradely labeled neurons in area 4 in case D8408R. Note the large number of labeled cells in layer III and the relatively few labeled neurons in layer V. Scale bar, $100 \mu \mathrm{m}$.

prefrontal cortex, or even within single cytoarchitectonic areas. In some cases, these differences were quite marked, with some areas containing cells in layers III-VI, while immediately adjacent areas contained labeled cells only in layers IV and V. The authors relate these changes in laminar distribution to differences in the relative densities of cell labeling noted within different prefrontal areas. They propose that the caudate nucleus may be innervated by 2 differently organized areas in the prefrontal cortex - one in which supra- and infragranular neurons give rise to a dense neostriatal projection, and a second in which granular and infragranular cells give rise to a lighter projection. While this may be so, it should also be noted that a particular neuronal density and distribution pattern within a given cytoarchitectonic area may simply reflect the location and extent of a particular caudate injection. This same cortical area may appear different in terms of the density and distribution of la- beled cells after injections are placed in different caudate regions. In addition, the relative distribution of neurons within all primate prefrontal areas examined showed, in each instance, that the majority of labeled neurons were located in layer $\mathrm{V}$, outnumbering those in layer III by almost $2: 1$ in heavily labeled areas, and by as much as $20: 1$ in lightly labeled areas. Thus, although there is some variation in the percentage of labeled neurons within laminae of the primate prefrontal region, the overall distribution of labeled neurons still places the majority of them in layer $\mathrm{V}$, and in no instance does the percentage of labeled cells in supragranular layers exceed that of infragranular label. This overall picture is similar to the one we report in the dog.

In contrast, the laminar distribution of corticostriatal neurons in carnivore and primate sensorimotor regions appears to differ appreciably. Although corticostriatal neurons are positioned within multiple laminae in the carnivore sensorimotor area $(\mathrm{Ki}$ tai et al., 1976; Oka, 1980; Royce, 1982, 1983; Kubozono et al., 1986), it seems that in primates, corticostriatal neurons in the sensorimotor region are found exclusively in layer $\mathrm{V}$ (Jones et al., 1977). One reason for this difference in laminar origin might lie with the methodology used to examine these neurons. In the primate study, HRP was processed with the DAB method of LaVail et al. (1973), which has been shown to be less sensitive to the presence of HRP than the TMB method (Mesulam, 1982). The use of a more sensitive chromagen may reveal that sensorimotor corticostriatal projections arise from supragranular layers as well. In the rat, the use of a more sensitive tracer ( ${ }^{125}$ I-tetanus toxin) revealed retrogradely labeled corticostriatal neurons within layers III-V (Schwab et al., 1977), while other studies using HRP and DAB showed labeling only in layer V (Hedreen, 1977; Wise and Jones, 1977; Veening et al., 1980).

Another possibility is that the differences in laminar distribution seen between primates and carnivores reflects a real species difference. However, this would seem to apply only to corticostriatal neurons, since other neurons projecting subcortically to nuclei in the carnivore thalamus and brain stem (Kosmal et al., 1983; Royce, 1983; Nakano et al., 1985; Velayos and Reinoso-Suárez, 1985) lie in layers V and VI, just as they do in the monkey (see Jones, 1984, for review).

Previous authors have suggested that the widespread laminar origin associated with pericruciate corticostriatal neurons may be related to specific patterns of collateralization (Royce, 1982) or to shared telencephalic characteristics with cortical association neurons (Arikuni and Kubota, 1986). With regard to collateralization, it has been hypothesized that corticostriatal fibers may consist of axon collaterals of neurons projecting to other cortical or subcortical sites (Royce, 1982), and several studies have reported that axons passing to thalamic (Royce, 1983) or brain stem-spinal regions (Oka and Jinnai, 1978; Jinnai and Matsuda, 1979; Donoghue and Kitai, 1981) send collaterals to the neostriatum. Those neurons giving rise to neostriatal collaterals are located in layer V (and VI in the case of corticothalamic cells) and may comprise a group of neurons anatomically and physiologically distinct from those that project only to the caudate nucleus (Jinnai and Matsuda, 1979). Although it appears that only a very small percentage of corticostriatal projections may be classified as collaterals of corticothalamic axons (Royce, 1982), the full extent of collateralization to the neostriatum from cortical neurons projecting to other subcortical or cortical areas has yet to be determined.

Arikuni and Kubota (1986) suggested that neurons making 
up corticocortical and corticostriatal systems may be related functionally, since the laminar origins of both systems are similar, that is, they both involve supra- and infragranular layers. Along these lines, it is possible that some recent data reported by Barbas (1986) and Barbas and Mesulam (1981, 1985) on the organization of corticocortical projections in the monkey may be of relevance to the present study. They have reported that the laminar distribution of cortical association neurons projecting to prefrontal and frontal eye-field regions may differ, depending on the cytoarchitectonic characteristics of the area of origin. Neurons projecting to the prefrontal region that are located in less well-differentiated cortical areas (for example, in limbic and polar temporal areas) are mainly situated within infragranular layers, while those located in more highly differentiated cortical regions, such as the primary motor area, are mostly found within supragranular layers (Barbas, 1986). This change in laminar distribution of corticocortical neurons may be compared to that seen with respect to corticocaudate projections in the dog, in which projections arising from the poorly laminated prefrontal region originate in layer $\mathrm{V}$, while those arising from the distinctly laminar pericruciate region originate predominantly from layer III.

Another factor to consider is the possible relationship between the laminar location of corticostriatal neurons and the terminal arborizations of particular types of thalamocortical inputs. For example, in the dog, thalamocortical projections arising from the ventral anterior nucleus terminate in layers I and III of the pericruciate region (Stanton et al., 1986). In the cat, projections from the ventral lateral nucleus have also been reported to terminate in layer III (Hendry et al., 1979) and in layers I and III (Rausell and Avendaño, 1985) of the sensorimotor cortex. This suggests that corticostriatal neurons located in layer III of the pericruciate region might be in a particularly good position to receive thalamic inputs arising from motor relay nuclei. In contrast, the corticostriatal neurons in layer $\mathrm{V}$ of the prefrontal cortex might be more influenced by intralaminar thalamic afferents, which have been shown to terminate heavily in layers I and VI in the cat (Kaufman and Rosenquist, 1985) and V and VI in the rat (Herkenham, 1980).

Although these data from primates, cats, and dogs suggest that there might be a relationship between the laminar distribution of corticostriatal neurons and that of corticocortical neurons or thalamocortical afferents, such a relationship has not yet been established for these neurons and inputs in any single spccics. The data reported in the present study, showing differences in the laminar distribution of corticostriatal neurons, may provide a basis from which a further comparison between corticostriatal neurons and other cortical afferent or efferent systems may be made.

\section{References}

Adrianov, O. S., and T. A. Mering (1964) Atlas of the Canine Brain, Edwards Bros., Ann Arbor, MI.

Akert, K. (1964) Comparative anatomy of the frontal cortex and thalamocortical connections. In The Frontal Granular Cortex and Behavior, J. M. Warren and K. Akert, eds., pp. 372-396, McGraw-Hill, New York.

Arikuni, T., and K. Kubota (1986) The organization of prefrontocaudate projections and their laminar origin in the macaque monkey: $\mathrm{A}$ retrograde study using HRP-gel. J. Comp. Neurol. 244: 492-510.

Barbas, H. (1986) Pattern in the laminar origin of corticocortical connections. J. Comp. Neurol. 252: 415-422.

Barbas, H., and M. M. Mesulam (1981) Organization of afferent input of subdivisions of area 8 in the rhesus monkey. J. Comp. Neurol. 200: 407-431.

Barbas, H., and M. M. Mesulam (1985) Cortical afferent input to the principalis region of the rhesus monkey. Neuroscience 15:619-637.

Brutkowski, S. (1964) Prefrontal cortex and drive inhibition. In The Frontal Granular Cortex and Behavior, J. M. Warren and K. Akert, eds., pp. 242-270, McGraw-Hill, New York.

Donoghue, J. P., and S. T. Kitai (1981) A collateral pathway to the neostriatum from corticofugal neurons of the rat sensory-motor cortex: An intracellular HRP study. J. Comp. Neurol. 201: 1-13.

Górska, T. (1974) Functional organization of cortical motor areas in adult dogs and puppies. Acta Neurobiol. Exp. 34: 171-203.

Górska, T., and K. Dutkiewicz (1979) Some observations on the cytoarchitecture and size of pyramidal cells in layer $\mathrm{V}$ of the motor cortex (MI) in the dog. Folia Biol. (Krakow) 27: 65-82.

Hedreen, J. C. (1977) Corticostriatal cells identified by the peroxidase method. Neurosci. Lett. 4: 1-7.

Hendry, S. H. C., E. G. Jones, and J. Graham (1979) Thalamic relay nuclei for cerebellar and certain related fiber systems in the cat. J. Comp. Neurol. 185: 679-714.

Herkenham, M. (1980) Laminar organization of thalamic projections to the rat neocortex. Science 207: 532-535.

Itoh, K., S. Konishi, N. Nomura, Y. Mizuno, Y. Nakamura, and T. Sugimoto (1979) Application of coupled oxidase reaction to electron microscopic demonstration of horseradish peroxidase: Cobalt-glucose oxidase method. Brain Res. 175: 341-346.

Jinnai, K., and Y. Matsuda (1979) Neurons of the motor cortex projecting commonly on the caudate nucleus and the lower brainstem in the cat. Neurosci. Lett. 13: 121-126.

Jones, E. G. (1984) Laminar distribution of cortical efferent cells. In Cerebral Cortex, Vol. 1: Cellular Components of the Cerebral Cortex, A. Peters and E. G. Jones, eds., pp. 521-553, Plenum, New York.

Jones, E. G., J. D. Coulter, H. Burton, and R. Porter (1977) Cells of origin and terminal distribution of corticostriatal fibers arising in the sensory-motor cortex of monkeys. J. Comp. Neurol. 173: 53-80.

Kaufman, E. F. S., and A. C. Rosenquist (1985) Efferent projections of the thalamic intralaminar nuclei in the cat. Brain Res. 335: 257279.

Kitai, S. T., J. D. Kocsis, and J. Wood (1976) Origin and characteristics of cortico-caudate afferents: An anatomical and electrophysiological study. Brain Res. 118: 137-141.

Konorski, J. (1972) Some hypotheses concerning the functional organization of prefrontal cortex. Acta Neurobiol. Exp. 32: 595-613.

Kosmal, A. (1981a) Subcortical connections of the prefrontal cortex in dogs: Afferents to the proreal gyrus. Acta Neurobiol. Exp. 41: 6985

Kosmal, A. (1981b) Subcortical connections of the prefrontal cortex in dogs: Afferents to the medial cortex. Acta Neurobiol. Exp. 41:339356.

Kosmal, A., and J. Dabrowska (1980) Subcortical connections of the prefrontal cortex in dogs: Afferents to the orbital gyrus. Acta Neurobiol. Exp. 40: 593-608.

Kosmal, A., I. Stepniewska, and G. Markow (1983) Laminar organization of efferent connections of the prefrontal cortex in the dog. Acta Neurobiol. Exp. 43: 115-127.

Kosmal, A., G. Markow, and I. Stepniewska (1984) The presylvian cortex as a transitional prefronto-motor zone in dog. Acta Neurobiol. Exp. 44: 273-287.

Kreiner, J. (1961) Myeloarchitectonics of the frontal cortex of the dog. J. Comp. Neurol. 116: 117-133.

Kreiner, J. (1964) Myeloarchitectonics of the sensori-motor cortex in dog. J. Comp. Neurol. 122: 181-200.

Kubozono, T., K. Nakano, A. Tokushige, Y. Hasegawa, and M. Kohno (1986) Topographical organization of the projections from the cerebral cortex to the head of the caudate nucleus. A horseradish peroxidase study in the cat. Neuroscience 19:113-123.

LaVail, J. H., K. R. Winston, and A. Tish (1973) A method based on retrograde intraaxonal transport of protein for identification of cell bodies of axons terminating within the CNS. Brain Res. 58: 470-477.

Lewis, R. S., S. T. Sakai, and D. Tanaka, Jr. (1981) Thalamic projections of the posterior parietal area in the dog: Afferent organization and acetylthiocholinesterase histochemistry. Soc. Neurosci. Abstr. 7: 757.

Mesulam, M. M. (1982) Principles of horseradish peroxidase neurohistochemistry and their applications for tracing neural pathways- 
axonal transport, enzyme histochemistry, and light microscopic analysis. In Tracing Neural Connections with Horseradish Peroxidase, M. M. Mesulam, ed., pp. 1-15I, Wiley, Chichester, UK.

Nakano, K., M. Kohno, Y. Hasegawa, and A. Tokushige (1985) Cortical and brain stem afferents to the ventral thalamic nuclei of the cat demonstrated by retrograde axonal transport of horseradish peroxidase. J. Comp. Neurol. 231: 102-120.

Narkiewicz, O., and S. Brutkowski (1967) The organization of projections from the thalamic mediodorsal nucleus to the prefrontal cortex of the dog. J. Comp. Neurol. 129: 361-374.

Oka, H. (1980) Organization of the cortico-caudate projections. A horseradish peroxidase study in the cat. Exp. Brain Res. 40:203-208.

Oka, H., and K. Jinnai (1978) Common projection of the motor cortex to the caudate nucleus and the cerebellum. Exp. Brain Res. 31:3142.

Rausell, E., and C. Avendaño (1985) Thalamocortical neurons projecting to superficial and deep layers in parietal, frontal, and prefrontal regions in the cat. Brain Res. 347: 159-165.

Royce, G. J. (1982) Laminar origin of cortical neurons which project upon the caudate nucleus: A horseradish peroxidase investigation in the cat. J. Comp. Neurol. 205: 8-29.

Royce, G. J. (1983) Cortical neurons with collateral projections to both the caudate nucleus and the centromedian-parafascicular thalamic complex: A fluorescent retrograde double labeling study in the cat. Exp. Brain Res. 50:157-165.

Schwab, M., Y. Agid, L. Glowinski, and H. Thoenen (1977) Retrograde axonal transport of ${ }^{125}$ I-tetanus toxin as a tool for tracing fiber connections in the central nervous system; connections of the rostral part of the rat neostriatum. Brain Res. 126: 211-224.
Shook, B. L., B. P. Abramson, and L. M. Chalupa (1984) An analysis of the transport of WGA-HRP in the cat's visual system. J. Neurosci. Methods 11: 65-77.

Stanton, G. B., D. Tanaka, Jr., S. T. Sakai, and O. I. Weeks (1986) Thalamic afferents to cytoarchitectonic subdivisions of area 6 on the anterior sigmoid gyrus of the dog: A retrograde and anterograde tracing study. J. Comp. Neurol. 252: 446-467.

Tanaka, D., Jr. (1987) Neostriatal projections from cytoarchitectonically defined gyri in the prefrontal cortex of the dog. J. Comp. Neurol 261: 48-73.

Tanaka, D., Jr., T. Górska, and K. Dutkiewicz (1979) Differential projections to the neostriatum from the arm areas of the primary and supplementary motor cortices in the dog. Brain Res. 172: 150-154.

Tanaka, D., Jr., T. Górska, and K. Dutkiewicz (1981) Corticostriate projections from the primary motor cortex in the dog. Brain Res. 209: 287-303.

Tanaka, D., Jr., S. T. Sakai, and T. Górska (1983) Corticothalamic projections from postcruciate area 4 in the dog. J. Comp. Neurol. 214: 17-31.

Veening, J. G., F. M. Cornelissen, and P. A. J. M. Lieven (1980) The topical organization of the afferents to the caudatoputamen of the rat. A horseradish peroxidase study. Neuroscience 5: 1253-1268.

Velayos, J. L., and F. Reinoso-Suárez. (1985) Prosencephalic afferents to the mediodorsal thalamic nucleus. J. Comp. Neurol. 242: 161181

Wise, S. P., and E. G. Jones (1977) Cells of origin and terminal distribution of descending projections of the rat somatic sensory cortex. J. Comp. Neurol. 175: 129-158. 